\title{
HMGB1 Attenuates Anti-Metastatic Defense of the Lymph Nodes in Colorectal Cancer
}

\author{
Yukiko Moriwaka ${ }^{\text {Yi Luo }}{ }^{\text {a Hitoshi Ohmori }}{ }^{\text {a }}$ Kiyomu Fujii ${ }^{\mathrm{a}}$ \\ Naokuni Tatsumoto ${ }^{b}$ Tomonori Sasahira $^{a}$ Hiroki Kuniyasu $^{a}$ \\ a Department of Molecular Pathology, Nara Medical University School of Medicine, Kashihara, and \\ ${ }^{b}$ Department of Surgery, Miyoshi Central Hospital, Miyoshi, Japan
}

\section{Key Words}

Colorectal cancer $\cdot$ Liver metastasis • Nodal metastasis •

HMGB1 $\cdot$ Lymph vessel density $\cdot$ Macrophages

\begin{abstract}
Background: Cancer-secreted high mobility group 1 (HMGB1) induces apoptosis of macrophages and suppresses the host anti-cancer immune system. Objective: We here examined the effect of HMGB1 on macrophages in the lymph nodes of colorectal cancer (CRC) patients. Methods: Regional lymph nodes of 50 Dukes C CRCs were compared with 50 Dukes B CRCs. Results: Dukes $C$ tumors exhibited higher HMGB1 labeling indices and higher HMGB1 concentrations in primary tumors than Dukes B CRCs. Macrophages in the regional lymph nodes were decreased in non-metastasized nodes as well as metastasized nodes in Dukes C cases, whereas macrophage numbers in Dukes B nodes were higher than in Dukes $C$ nodes. Nodal HMGB1 concentration was higher in Dukes $C$ nodes than in Dukes B nodes, being inversely correlated with macrophage numbers. Nodal HMGB1 concentration was correlated with HMGB1 concentration and lymph vessel density in the primary tumors. Conclusion: These data suggest that HMGB1 secreted from primary tumors spread to the regional lymph nodes decreases the number of macrophages to attenuate the anti-metastatic defense of the lymph nodes in patients with CRCs.
\end{abstract}

Copyright $\odot 2010$ S. Karger AG, Basel

\section{Introduction}

The major cause of death from gastrointestinal cancer is the progressive growth of metastases that are resistant to therapy. Metastasis is a highly selective process that consists of a series of sequential, interrelated steps [1]. In cancer, the activation of macrophages, which have anticancer properties, is suppressed, and the production of vascular endothelial growth factor (VEGF) [2] and platelet-derived endothelial cell growth factor [3], which have tumor-promoting activity, is induced. We reported that macrophage infiltration is significantly reduced in metastatic colon cancer, in which the levels of high mobility group 1 (HMGB1) are elevated [4].

The protein HMGB1, which is also called amphoterin, plays a dual role [5-8]. As a structural chromosome protein, it is involved in gene transcription [8] and DNA repair [9]. It is also a secreted cytokine and is associated with neural development $[10,11]$, cancer progression and inflammation [8]. Secreted HMGB1 accelerates cancer cell growth, motility and invasion, and hence enhances cancer metastasis via the activation of a specific membrane receptor (receptor for advanced glycation end products: RAGE), which is expressed in cancer cells [1218]. HMGB1 also acts as an anti-apoptotic factor by inducing the expression of $\mathrm{Bcl}-2$ in cancer cells [11].

HMGB1 plays a pivotal role in the immune system. It acts as a late inflammatory cytokine by activating mac-

\section{KARGER}

Fax +4161306 1234 E-Mail karger@karger.ch www.karger.com
(C) 2010 S. Karger AG, Basel

$1015-2008 / 10 / 0771-0017 \$ 26.00 / 0$

Accessible online at:

www.karger.com/pat
Dr. Hiroki Kuniyasu

Department of Molecular Pathology, Nara Medical University

840 Shijo-cho, Kashihara, Nara, 634-8521 (Japan)

Tel. +81 74422 3051, Fax +81 744257308

E-Mailcooninh@zb4.so-net.ne.jp 
rophages in response to lipopolysaccharides [8] and increases the secretion of the inflammatory cytokines interleukin- $1 \beta$, interferon- $\gamma$ and tumor necrosis factor- $\alpha$, which worsen septic shock [19]. A high level of intratumoral HMGB1 in colorectal cancer (CRC) induces apoptosis by activating c-Jun N-terminal kinase (JNK) in tumor-associated macrophages (TAMs) [20]. HMGB1-induced TAM inhibition is associated with the metastasis of colon cancer to lymph nodes [4]. Taking these findings into account, HMGB1 might also affect other immune cells of monocyte lineage in target organs of metastasis. Indeed, monocyte-dendritic cells are inhibited by HMGB1 in lymph nodes [21]. In the present study, we attempted to elucidate the inhibitory effects of CRC-derived HMGB1 on sinus macrophages in lymph nodes and liver, and their effects on metastasis formation.

\section{Materials and Methods}

\section{Surgical Specimens}

Formalin-fixed, paraffin-embedded archival surgical specimens from 100 patients with primary adenocarcinomas of the colon that had invaded the subserosal layer were randomly selected from the Nara Medical University Hospital and the Miyoshi Central Hospital (table 1). Of 100 cases, 50 were Dukes' stage B (tumor invades beyond the muscularis propria without lymph node metastasis; all cases invaded the subserosal layer) and 50 were stage C (any cases with lymph node metastasis; all cases invaded the subserosal layer). In all cases, fresh tissue was obtained from primary tumors and lymph nodes. Because written informed consent was not obtained, identifying information for all samples was removed before analysis for strict privacy protection; the procedure was in accordance with the Ethical Guidelines for Human Genome/Gene Research enacted by the Japanese Government.

\section{Immunohistochemistry}

Consecutive $4-\mu \mathrm{m}$ sections were immunohistochemically stained using the immunoperoxidase technique described previously [22]. Antibodies to HMGB1 (mouse monoclonal antibody, Abcam, Cambridge, UK) and CD68 (DAKO, Carpinteria, Calif., USA) were used at a concentration of $0.5 \mu \mathrm{g} / \mathrm{ml}$. Secondary antibodies (Medical and Biological Laboratories, Nagoya, Japan) were employed at a concentration of $0.2 \mu \mathrm{g} / \mathrm{ml}$. The specimens were color developed with diaminobenzidine hydrochloride (DAKO). Meyer's hematoxylin (Sigma, St. Louis, Mo., USA) was used for counterstaining. CD68-positive cells were counted from 1,000 cells observed by microscopic examination.

\section{Enzyme-Linked Immunosorbent Assay}

Frozen tissues of the primary tumors, lymph nodes and livers were homogenized by 40 strokes of Dounce's pestol B in Dounce buffer (10 mM Tris- $\mathrm{HCl}, \mathrm{pH} 8.0,1 \mathrm{mM} \mathrm{MgCl}_{2}$ and $0.25 \mathrm{M}$ sucrose). The homogenate was centrifuged at $1,000 \mathrm{~g}$ for $10 \mathrm{~min}$ at $4{ }^{\circ} \mathrm{C}$. The supernatant was recovered and mixed with the same amount of $2 \times$ lysis buffer $(100 \mathrm{~mm}$ Tris- $\mathrm{HCl}, \mathrm{pH}$ 7.4, $300 \mathrm{~mm} \mathrm{NaCl}, 10 \mathrm{~mm}$
Table 1. Characteristics of the CRC cases

\begin{tabular}{|c|c|c|c|}
\hline & Dukes B & Dukes C & $\mathrm{p}$ value \\
\hline Metastasis & none & lymph nodes & \\
\hline Patients, n & 50 & 50 & \\
\hline Males:females & $28: 22$ & $32: 18$ & NS \\
\hline Age & $42-86$ & $51-92$ & NS \\
\hline \multicolumn{4}{|l|}{ Location } \\
\hline Cecum & 3 & 2 & \\
\hline Right colon & 19 & 15 & \\
\hline Left colon & 21 & 22 & \\
\hline Rectum & 7 & 11 & NS \\
\hline Size, $\mathrm{mm}$ & $49(27-82)$ & $45(25-68)$ & NS \\
\hline \multicolumn{4}{|l|}{ Depth of invasion } \\
\hline Muscularis propria & 5 & 3 & \\
\hline Subserosa & 28 & 26 & \\
\hline Serosa exposed & 17 & 21 & NS \\
\hline \multicolumn{4}{|l|}{ Nodal metastasis } \\
\hline 0 & 50 & 0 & \\
\hline 1-3 nodes & 0 & 29 & \\
\hline$>3$ nodes & 0 & 21 & NS \\
\hline
\end{tabular}

Pathological stage was determined according to the classification of Sobin and Wittekind [37].

ethylenediaminetetraacetic acid, $100 \mu \mathrm{g} / \mathrm{ml}$ phenylmethylsulfonyl fluoride, $2 \mu \mathrm{g} / \mathrm{ml}$ aprotinin and $1.0 \%$ Nonidet P-40). The mixture was used for ELISA. The nuclear pellets were discarded to avoid contamination of nuclear HMGB1. Concentrations of HMGB1 were assessed using the HMGB1 ELISA kit (Shinotest, Tokyo, Japan) according to the manufacturer's instruction.

\section{Statistical Analyses}

Statistical analyses of experimental data were done by MannWhitney $U$ test, ANOVA, and $\chi^{2}$ test. Statistical significance was defined as a two-sided $\mathrm{p}$ value $<0.05$.

\section{Results}

\section{Expression of HMGB1 in Lymph Node Metastases from CRCs}

HMGB1 expression was examined by immunohistochemistry in 100 specimens obtained from CRC patients (fig. 1). We counted HMGB1-positive nuclei and determined the percentage of positive cells (HMGB1 labeling index; fig. 1a, b). The HMGB1 labeling index was higher in Dukes $\mathrm{C}$ tumors (nodal metastasis present) than in Dukes B tumors (nodal metastasis absent; fig. 1c; p < 0.001). The HMGB1 concentration in tumor tissue was also examined (fig. 1d); it was higher in Dukes $\mathrm{C}$ tumors than in Dukes B tumors $(p<0.0001)$. 

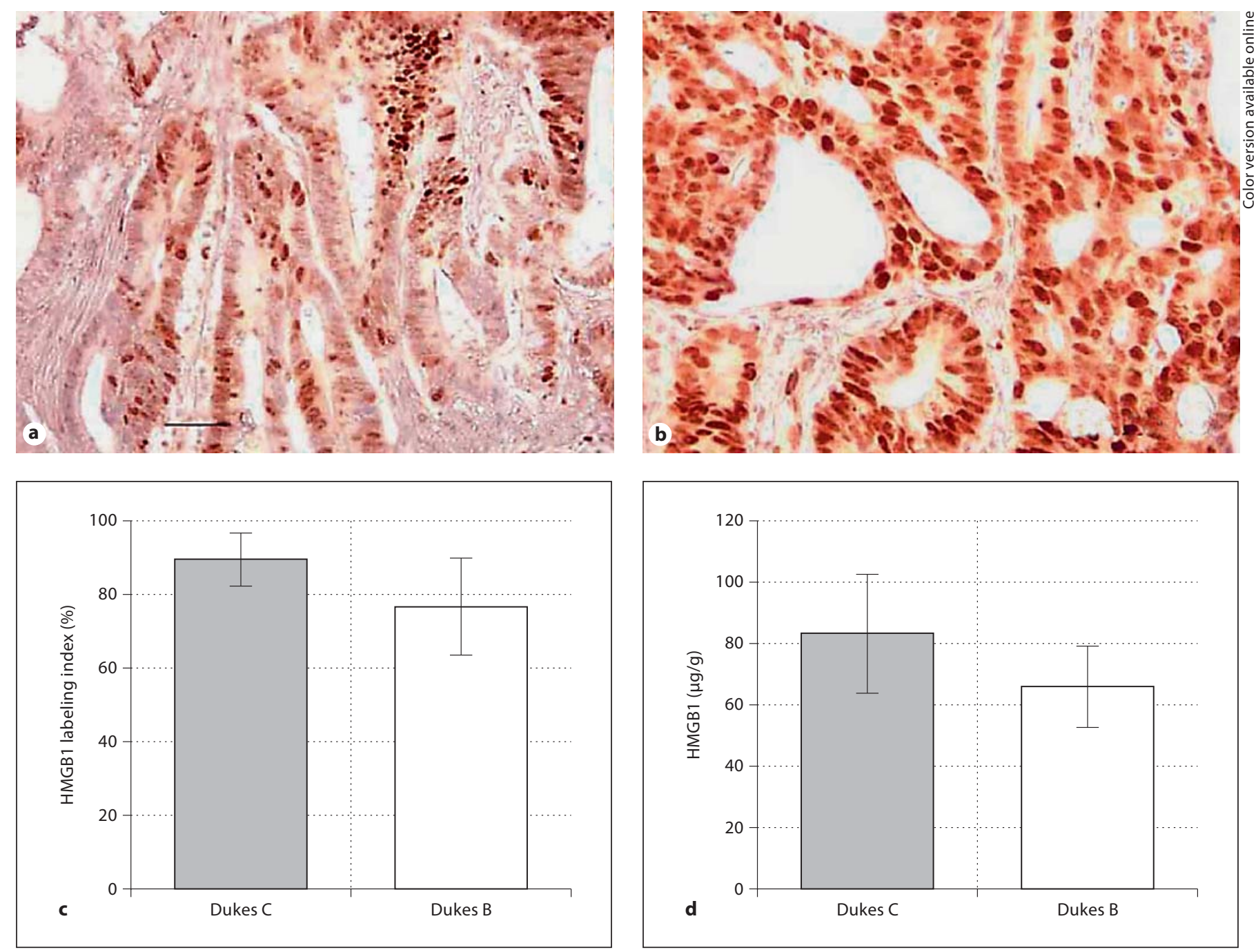

Fig. 1. HMGB1 expression in CRCs. a, b HMGB1 immunohistochemistry of Dukes B (a) and Dukes C tumors (b). The HMGB1 labeling indices of the two tumor types were 48 and 83\%, respectively. Bar $=50 \mu \mathrm{m}$. c, d HMGB1 expression was assessed on the basis of the HMGB1 labeling index (c, p = 0.0011) and HMGB1 concentration $(\mathbf{d}, \mathrm{p}=0.001)$ in the primary tumors. Error bars indicate SD.

Number of Macrophages in the Lymph Nodes in the Vicinity of CRC

The number of macrophages in the regional lymph nodes was determined in the CRC patients (fig. 2). Examination of the lymph nodes near Dukes $B$ tumors revealed many CD68-positive macrophages in the areas surrounding the lymph sinus (fig. 2a). In contrast, few CD68-positive macrophages were observed in lymph nodes with and without metastases from Dukes $C$ tumors (fig. 2b, c). Further, significantly fewer macrophages were found in the lymph nodes with and without metastases from Dukes $\mathrm{C}$ tumors than in the lymph nodes adjacent to Dukes B tumors (fig. 2d; $p<0.0001$ ).

\section{HMGB1 Concentration in the Lymph Nodes in the Vicinity of CRCs}

We next examined the HMGB1 concentration in the lymph nodes in the vicinity of CRCs (50 non-metastatic lymph nodes in the vicinity of 50 Dukes $C$ tumors and 50 lymph nodes in the vicinity of 50 Dukes B tumors; fig. 3). Cancer cells secrete large amounts of HMGB1; therefore, we did not use metastatic lymph nodes in the 

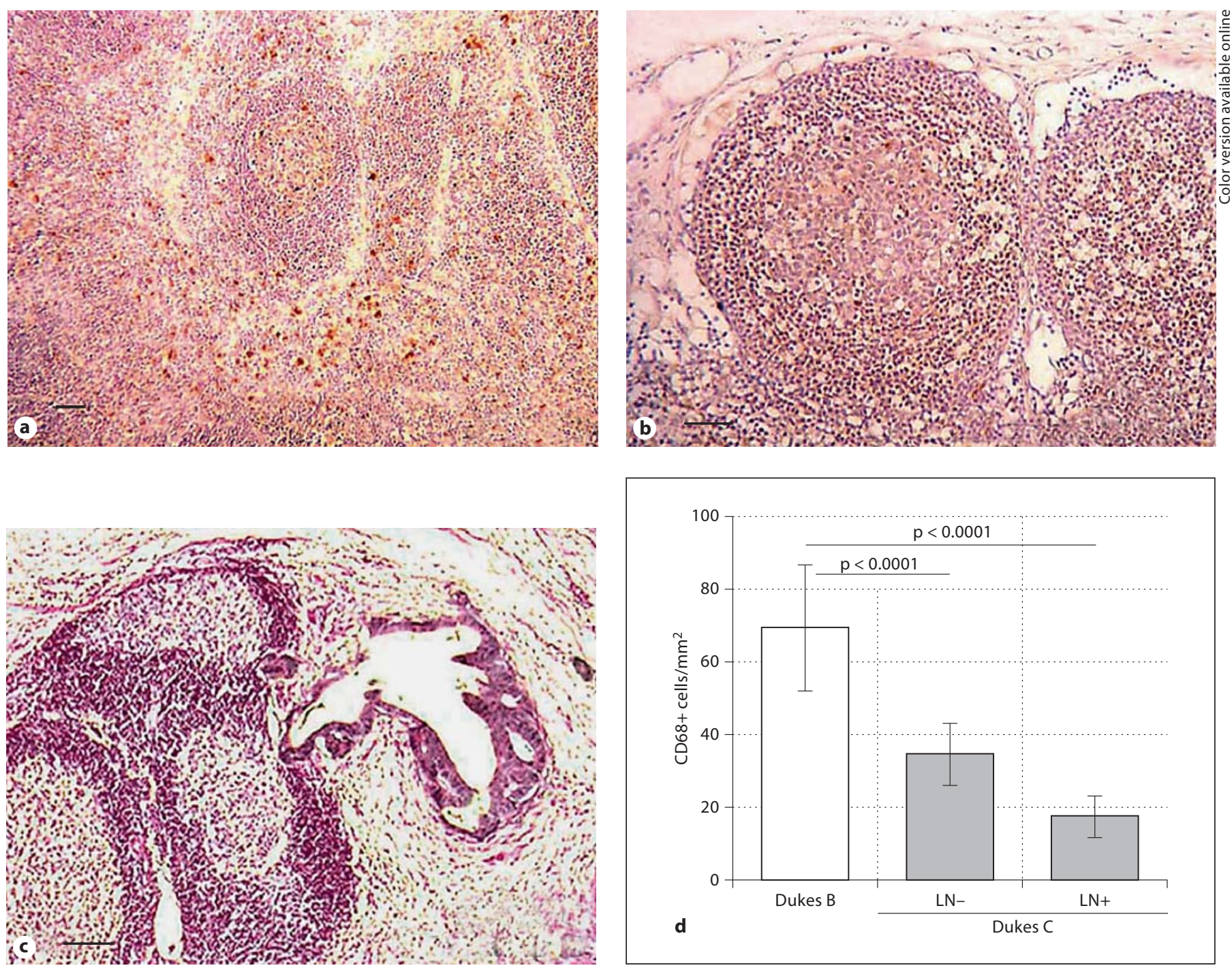

Fig. 2. Macrophages in lymph nodes situated near CRCs (a-c). CD68 immunostaining of non-metastatic lymph nodes of a patient with Dukes B (a) and a patient with Dukes C tumor (b), and in a metastatic node in a patient with a Dukes C tumor (c). Bar $=100 \mu \mathrm{m}$. d Number of CD68-positive macrophages in lymph nodes with (LN+) and without metastasis (LN-) situated near CRCs. Error bars indicate SD.

vicinity of Dukes $\mathrm{C}$ tumors. The HMGB1 concentration was higher in the lymph nodes near Dukes $C$ tumors than in those near Dukes B tumors (fig. 3a; $\mathrm{p}=0.0011$ ). The number of macrophages and HMGB1 concentration in the lymph nodes were well correlated with both Dukes $B$ and Dukes C tumors (fig. 3b; $p<0.0001$ ). The HMGB1 concentration in the lymph nodes correlated with that in the primary tumors in the case of both Dukes $\mathrm{B}$ and Dukes $C$ tumors (fig. $3 c ; p<0.0001$ ). Lymph vessel density (LVD) in the primary tumors was assessed by D2-40 immunostaining (fig. 3d). LVD was higher in Dukes C tumors than in Dukes B tumors ( $\mathrm{p}<0.0001)$. To assess the transfer of HMGB1 from the primary tumors to the lymph nodes, we calculated the ratio of the HMGB1 concentration in the lymph nodes to that in the primary tumors (node-primary HMGB1 ratio); this ratio was compared with the LVD in the primary tumors (fig. 3e). The ratios correlated with LVD in both Dukes B and Dukes C tumors $(p<0.0001)$. The Dukes B tumor with a nodeprimary ratio $<0.6$ did not overlap with Dukes $\mathrm{C}$ tumors. 

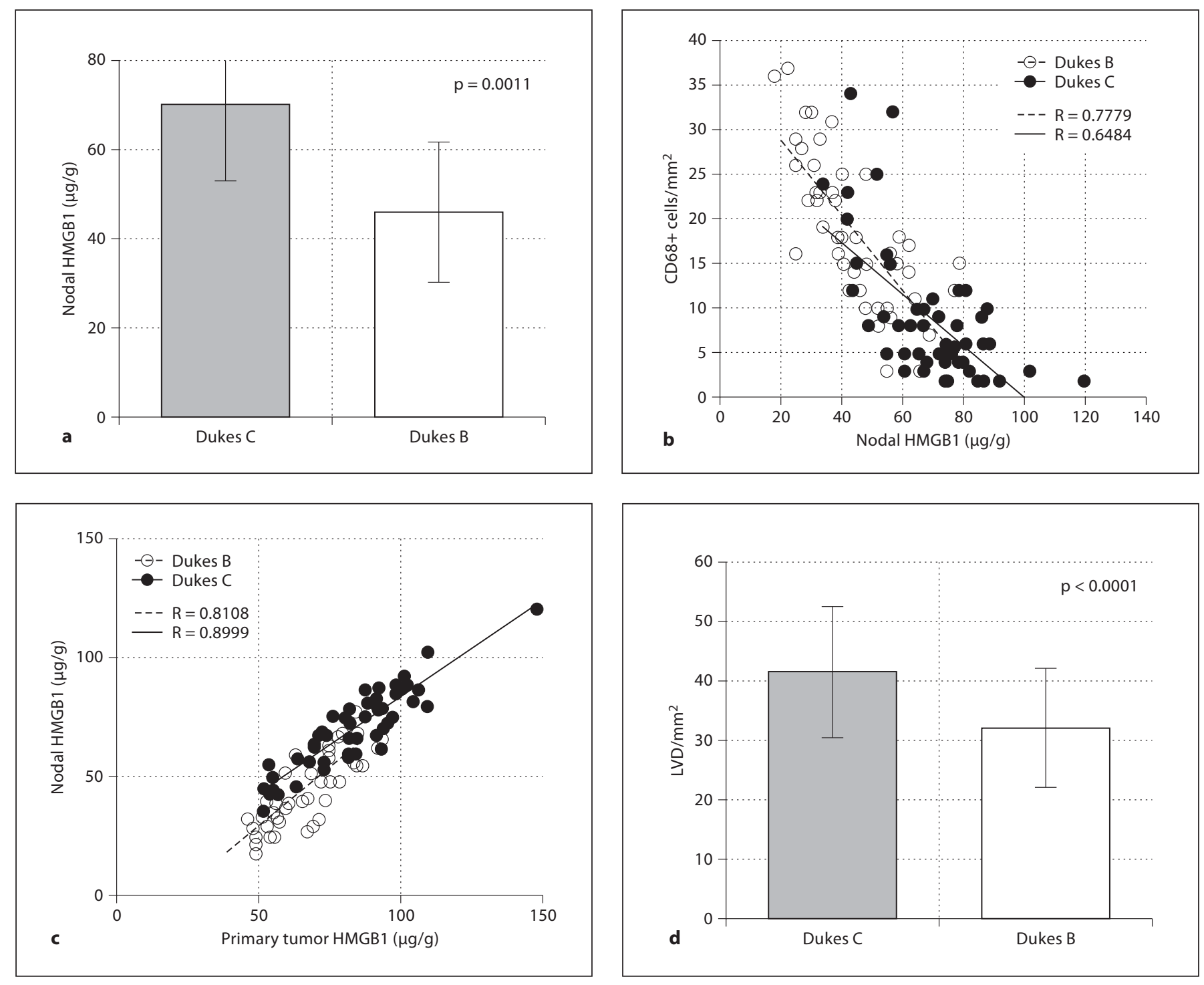

Fig. 3. Relationship between HMGB1 and the number of macrophages in the regional lymph nodes in Dukes B and C CRCs. a HMGB1 concentration in lymph nodes of 50 Dukes B CRCs and in non-metastatic nodes in the vicinity of 50 Dukes C CRCs. b Comparison between the number of CD68-positive macrophages in the lymph nodes and the nodal HMGB1 concentration. c Comparison of the nodal HMGB1 concentration with the HMGB1 concentration in the primary tumors. d LVD in CRCs. e Comparison of LVD with the ratio of the nodal HMGB1 concentration to the HMGB1 concentration in the primary tumor. Error bars indicate SD. R = Spearman's R.

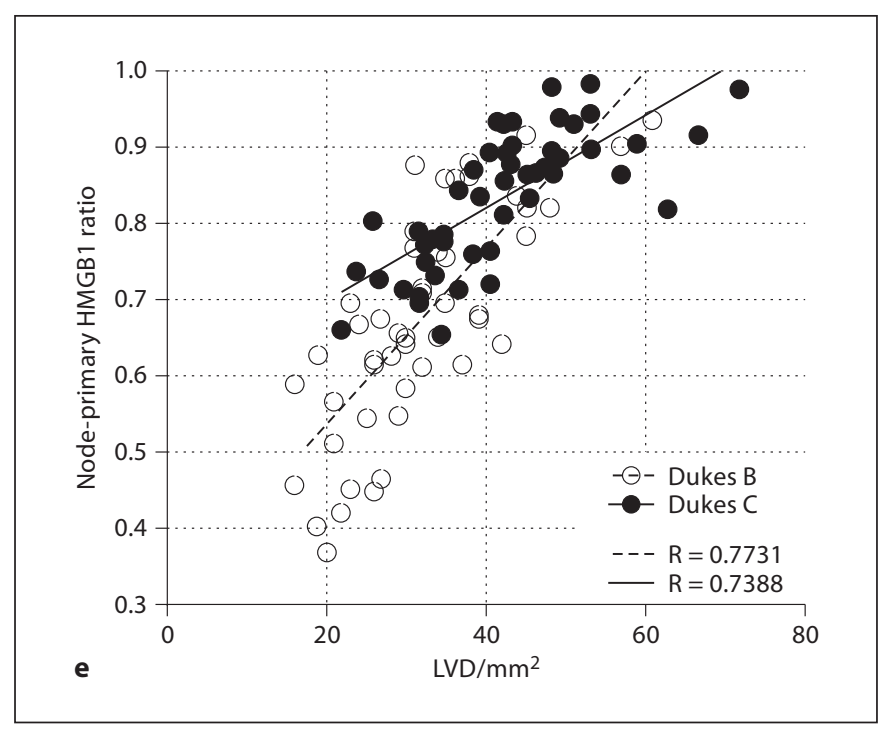




\section{Discussion}

In the present study, we determined the effect of HMGB1 secreted from CRC cells on macrophages/ Kupffer cells in the target organs of metastasis. We found that HMGB1 activates macrophages by RAGE-associated JNK activation and upregulation of caspase- 3 and caspase-9 $[20,21]$. The presence of HMGB1 in the primary CRCs was associated with a decrease in the number of TAMs and the development of lymph node metastasis [4, 23]. HMGB1 also decreases the number of monocytedendritic cells in the lymph nodes situated near CRCs [21]. In endotoxin shock, HMGB1 is released into the blood circulation and affects various organs $[19,24]$, suggesting that large amounts of secreted HMGB1 can affect remote organs such as the target organs of metastases from CRCs.

HMGB1 secreted from primary CRC tumors might be transferred to the lymph nodes via lymph ducts. Further, the node-primary HMGB1 ratio was well correlated with LVD. Both parameters were low in the case of Dukes B tumors but increased in the case of Dukes $C$ tumors. These findings suggest that enhanced lymphangiogenesis might not only facilitate HMGB1 entry into the lymph nodes but also deplete the primary tumor of HMGB1 [25]. Recently, we reported that HMGB1-induced MIA (melanoma inhibitory activity) promotes lymphangiogenesis through the upregulation of VEGF-C and VEGF-D in oral cancer [7]. MIA expression was also associated with lymph node metastasis in CRCs (data not shown). The transmigration of HMGB1 to the lymph nodes might be linked with lymphangiogenesis.

Macrophages of the lymph sinus participate in the immune response of the organs against metastatic cancer cells. Sinus macrophages mediate the phagocytosis of cancer cells attached to the sinus wall and destroy them in order to inhibit their metastasis [26, 27]. Sinus macrophages are also a part of an anti-cancer cytokine network involving TNF- $\alpha$ and IL-1 $\beta[28,29]$. The genes expressed in the sinus macrophages in the lymph nodes and liver were distinct from those expressed in the splenic sinus macrophages, e.g. the gene encoding C-type lectin [30, 31]. In prostate cancer metastasis, a decrease in the number of nodal immune cells involves a reduction in the number of sinus macrophages in the lymph nodes [32]. The inhibition of sinus macrophages in the target organs of metastasis results in attenuated anti-metastatic defense.

HMGB1 induces apoptosis in monocyte-lineage cells such as macrophages, Kupffer cells and monocyte-dendritic cells $[20,21]$ and activates JNK, which is associated with apoptosis [20,21]; monocyte-lineage cells express RAGE as an HMGB1 receptor [15]. Advanced end products (AGEs) are also common ligands of RAGE, which is accumulated in hyperglycemic and hyperoxidative conditions, especially those associated with diabetes mellitus [33-35]. While both HMGB1 and AGE activate RAGE, their effects are not similar [14]. Unlike HMGB1, AGE does not induce apoptosis even at high concentrations (data not shown). AGE also binds scavenger receptors to activate macrophages, triggering the production of inflammatory cytokines [36]. In CRC cells, HMGB1 activates extracellular signal-regulated kinase $1 / 2$ but not JNK to induce cell proliferation but not apoptosis. These different effects on RAGE, which depend on the types of ligands and cell lineages, warrant further examination.

Our data suggest that the neutralization of HMGB1 by anti-HMGB1 antibody inhibits liver metastasis. HMGB1 is expected to be a good marker for CRC metastasis and is a promising target for the inhibition of metastasis.

\section{Acknowledgments}

This work was supported in part by a Grant-in-Aid for Scientific Research from the Japanese Society for the Promotion of Science, Japan, and a Grant-in-Aid for Scientific Research from the Ministry of Health, Labor and Welfare, Japan.
References
Fidler IJ: The pathogenesis of cancer metastasis: the 'seed and soil' hypothesis revisited. Nat Rev Cancer 2003;3:453-458.

-2 Barbera-Guillem E, Nyhus JK, Wolford CC, Friece CR, Sampsel JW: Vascular endothelial growth factor secretion by tumor-infiltrating macrophages essentially supports tumor angiogenesis, and IgG immune complexes potentiate the process. Cancer Res 2002;62: 7042-7049.

\footnotetext{
3 Takahashi Y, Bucana CD, Liu W, Yoneda J, Kitadai Y, Cleary KR, et al: Platelet-derived endothelial cell growth factor in human colon cancer angiogenesis: role of infiltrating cells. J Natl Cancer Inst 1996;88:1146-1151.

-4 Kuniyasu H, Sasaki T, Sasahira T, Ohmori H, Takahashi T: Depletion of tumor-infiltrating macrophages is associated with amphoterin expression in colon cancer. Pathobiology 2004;71:129-136.
} 
5 Huttunen HJ, Rauvala H: Amphoterin as an extracellular regulator of cell motility: from discovery to disease. J Intern Med 2004;255: 351-366.

-6 Yang H, Wang H, Tracey KJ: HMG-1 rediscovered as a cytokine. Shock 2001;15:247253.

7 Sasahira T, Kirita T, Oue N, Bhawal UK, Yamamoto K, Fujii K, et al: High mobility group box-1-inducible melanoma inhibitory activity is associated with nodal metastasis and lymphangiogenesis in oral squamous cell carcinoma. Cancer Sci 2008;99:18061812 .

$>8$ Czura CJ, Wang H, Tracey KJ: Dual roles for HMGB1: DNA binding and cytokine. J Endotoxin Res 2001;7:315-321.

9 Huang JC, Zamble DB, Reardon JT, Lippard SJ, Sancar A: HMG-domain proteins specifically inhibit the repair of the major DNA adduct of the anticancer drug cisplatin by human excision nuclease. Proc Natl Acad Sci USA 1994;91:10394-10398.

-10 Parkkinen J, Raulo E, Merenmies J, Nolo R, Kajander EO, Baumann M, et al: Amphoterin, the $30-\mathrm{kDa}$ protein in a family of HMG1type polypeptides. Enhanced expression in transformed cells, leading edge localization, and interactions with plasminogen activation. J Biol Chem 1993;268:19726-19738.

-11 Huttunen HJ, Kuja-Panula J, Sorci G, Agneletti AL, Donato R, Rauvala H: Coregulation of neurite outgrowth and cell survival by amphoterin and S100 proteins through receptor for advanced glycation end products (RAGE) activation. J Biol Chem 2000; 275:40096-40105.

-12 Taguchi A, Blood DC, del Toro G, Canet A, Lee DC, Qu W, et al: Blockade of RAGE-amphoterin signalling suppresses tumour growth and metastases. Nature 2000;405: 354-360.

-13 Kuniyasu H, Oue N, Wakikawa A, Shigeishi H, Matsutani N, Kuraoka K, et al: Expression of receptors for advanced glycation endproducts (RAGE) is closely associated with the invasive and metastatic activity of gastric cancer. J Pathol 2002;196:163-170.

-14 Kuniyasu H, Chihara Y, Kondo H: Differential effects between amphoterin and advanced glycation end products on colon cancer cells. Int J Cancer 2003;104:722-727.

15 Kuniyasu H, Chihara Y, Takahashi T: Co-expression of receptor for advanced glycation end products and the ligand amphoterin associates closely with metastasis of colorectal cancer. Oncol Rep 2003;10:445-448.
16 Kuniyasu H, Chihara Y, Kondo H, Ohmori H, Ukai R: Amphoterin induction in prostatic stromal cells by androgen deprivation is associated with metastatic prostate cancer. Oncol Rep 2003;10:1863-1868.

17 Sasahira T, Kirita T, Bhawal UK, Ikeda M, Nagasawa A, Yamamoto K, et al: The expression of receptor for advanced glycation end products is associated with angiogenesis in human oral squamous cell carcinoma. Virchows Arch 2007;450:287-295.

18 Sasahira T, Kirita T, Bhawal UK, Yamamoto K, Ohmori H, Fujii K, et al: Receptor for advanced glycation end products (RAGE) is important in the prediction of recurrence in human oral squamous cell carcinoma. Histopathology 2007;51:166-172.

19 Wang H, Bloom O, Zhang M, Vishnubhakat JM, Ombrellino M, Che J, et al: HMG-1 as a late mediator of endotoxin lethality in mice. Science 1999;285:248-251.

20 Kuniyasu H, Yano S, Sasaki T, Sasahira T, Sone S, Ohmori H: Colon cancer cell-derived high mobility group 1/amphoterin induces growth inhibition and apoptosis in macrophages. Am J Pathol 2005;166:751-760.

21 Kusume A, Sasahira T, Luo Y, Isobe M, Nakagawa N, Tatsumoto N, et al: Suppression of dendritic cells by HMGB1 is associated with lymph node metastasis of human colon cancer. Pathobiology 2009;76:155-162.

22 Kuniyasu H, Yasui W, Shinohara H, Yano S, Ellis LM, Wilson MR, et al: Induction of angiogenesis by hyperplastic colonic mucosa adjacent to colon cancer. Am J Pathol 2000 157:1523-1535.

23 Sasahira T, Sasaki T, Kuniyasu H: Interleukin-15 and transforming growth factor $\alpha$ are associated with depletion of tumor-associated macrophages in colon cancer. J Exp Clin Cancer Res 2005;24:69-74.

24 Suda K, Kitagawa Y, Ozawa S, Saikawa Y, Ueda M, Abraham E, et al: Serum concentrations of high-mobility group box chromosomal protein 1 before and after exposure to the surgical stress of thoracic esophagectomy: a predictor of clinical course after sur gery? Dis Esophagus 2006;19:5-9.

25 Stacker SA, Achen MG, Jussila L, Baldwin $\mathrm{ME}$, Alitalo K: Lymphangiogenesis and cancer metastasis. Nat Rev Cancer 2002;2:573583.

26 van der Bij GJ, Oosterling SJ, Meijer S, Beelen $\mathrm{RH}$, van Egmond M: Therapeutic potential of Kupffer cells in prevention of liver metastases outgrowth. Immunobiology 2005;210 259-265.
27 Timmers M, Vekemans K, Vermijlen D, Asosingh K, Kuppen P, Bouwens L, et al: Interactions between rat colon carcinoma cells and Kupffer cells during the onset of hepatic metastasis. Int J Cancer 2004;112:793-802.

28 Khatib AM, Auguste P, Fallavollita L, Wang N, Samani A, Kontogiannea M, et al: Characterization of the host proinflammatory response to tumor cells during the initial stages of liver metastasis. Am J Pathol 2005;167: 749-759.

-29 Nagata H, Arai T, Soejima Y, Suzuki H, Ishii H, Hibi T: Limited capability of regional lymph nodes to eradicate metastatic cancer cells. Cancer Res 2004;64:8239-8248.

-30 Martens JH, Kzhyshkowska J, FalkowskiHansen M, Schledzewski K, Gratchev A, Mansmann U, et al: Differential expression of a gene signature for scavenger/lectin receptors by endothelial cells and macrophages in human lymph node sinuses, the primary sites of regional metastasis. J Pathol 2006; 208:574-589.

31 Ichii S, Imai Y, Irimura T: Initial steps in lymph node metastasis formation in an experimental system: possible involvement of recognition by macrophage C-type lectins. Cancer Immunol Immunother 2000;49:1-9.

>32 Gannon PO, Alam Fahmy M, Begin LR, Djoukhadjian A, Filali-Mouhim A, Lapointe $\mathrm{R}$, et al: Presence of prostate cancer metastasis correlates with lower lymph node reactivity. Prostate 2006;66:1710-1720.

33 Schmidt AM, Stern DM: RAGE: a new target for the prevention and treatment of the vascular and inflammatory complications of diabetes. Trends Endocrinol Metab 2000;11: 368-375.

34 Schmidt AM, Hori O, Cao R, Yan SD, Brett J, Wautier JL, et al: RAGE: a novel cellular receptor for advanced glycation end products. Diabetes 1996;45(suppl 3):S77-S80.

-35 Yamamoto Y, Yamagishi S, Yonekura H, Doi T, Tsuji H, Kato I, et al: Roles of the AGERAGE system in vascular injury in diabetes. Ann NY Acad Sci 2000;902:163-170.

$\checkmark 36$ Tesch GH: Role of macrophages in complications of type 2 diabetes. Clin Exp Pharmacol Physiol 2007;34:1016-1019.

37 Sobin LH, Wittekind C (eds): UICC TNM Classification of Malignant Tumors, ed 6. New York, Wiley, 2003. 